\title{
Bladder Carcinoma Infiltrating the Muscle of the Bladder Wall
}

National Cancer Institute

\section{Source}

National Cancer Institute. Bladder Carcinoma Infiltrating the Muscle of the Bladder Wall. NCl Thesaurus. Code C150572.

A carcinoma that arises from the bladder mucosa and invades the muscle of the bladder wall. 